\title{
Bioequivalence of Generic and Brand Name Clozapine in Korean Schizophrenic Patients: A Randomized, Two-Period, Crossover Study
}

\author{
Young Sup Woo', Hee-Ryung Wang', Bo-Hyun Yoon², Sang-Yeol Lee ${ }^{3}$, \\ Kwang Hun Lee ${ }^{4}$, Jeong Seok Seo ${ }^{5}$, and Won-Myong Bahk ${ }^{\circledR}$ \\ ${ }^{1}$ Department of Psychiatry, College of Medicine, The Catholic University of Korea, Seoul, Republic of Korea \\ ${ }^{2}$ Department of Psychiatry, Naju National Hospital, Naju, Republic of Korea \\ ${ }^{3}$ Department of Psychiatry, School of Medicine, Wonkwang University, Iksan, Republic of Korea \\ ${ }^{4}$ Department of Psychiatry, College of Medicine, Dongguk University, Gyeongju, Republic of Korea \\ ${ }^{5}$ Department of Psychiatry, School of Medicine, Konkuk University, Chungju, Republic of Korea
}

Objective Clozapine is the treatment of choice for refractory schizophrenia. The aim of this study was to compare the pharmacokinetics of the brand name (Clozaril) formulation and a generic formulation (Clzapine) of clozapine in Korean schizophrenic patients.

Methods A prospective, randomized, crossover study was conducted to evaluate the steady-state pharmacokinetic profiles of Clozaril and Clzapine. Schizophrenic patients were randomized to receive either the brand name or generic formulation (100 mg twice daily) for 10 days, followed by the other formulation for 10 days. Plasma samples were collected on the last day of each treatment period.

Results Twenty-two of 28 patients (78.6\%) completed the study. The mean $\mathrm{C}_{\text {max,ss }}$ values for Clzapine and Clozaril were 524.62 and $551.18 \mathrm{ng} / \mathrm{mL}$, and the mean $\mathrm{AUC}_{0-12}$ values were $4479.90 \mathrm{hr} \cdot \mathrm{ng} / \mathrm{mL}$ and $4724.56 \mathrm{hr} \cdot \mathrm{ng} / \mathrm{mL}$, respectively. The $90 \%$ CI values for the natural logarithmically transformed $\mathrm{C}_{\max , s \mathrm{~s}}$ and $\mathrm{AUC}_{0-12}$ ratios (Clzapine to Clozaril) after a single oral dose (100 mg) were 0.934 (0.8491.028 ) and 0.936 (0.869-1.008), respectively. Five patients (20.8\%) among 24 patients who took Clzapine reported 11 adverse events and six adverse events were reported by four patients (15.4\%) among 26 who took Clozaril; there were no significant differences on physical examination or in vital signs, ECG, and laboratory tests between groups.

Conclusion Generic clozapine (Clzapine) appears to be bioequivalent to brand name clozapine (Clozaril).

Psychiatry Investig 2015;12(3):356-360

Key Words Clozapine, Schizophrenia, Bioequivalence, Generic.

\section{INTRODUCTION}

Despite great advances in pharmacotherapy for schizophrenia, about $30-60 \%$ of patients do not respond well to antipsychotics. ${ }^{1}$ For these patients, clozapine remains the gold-standard treatment, although it was first synthesized over 50 years ago. ${ }^{2}$

\footnotetext{
Received: October 31, 2014 Revised: December 23, 2014 Accepted: December 26, 2014 Available online: July 6, 2015

$\triangle$ Correspondence: Won-Myong Bahk, MD, PhD

Department of Psychiatry, Yeouido St. Mary's Hospital, College of Medicine, The Catholic University of Korea, 10 63-ro, Yeongdeungpo-gu, Seoul 150-713, Republic of Korea

Tel: +82-2-3779-1250, Fax: +82-2-780-6577, E-mail: wmbahk@catholic.ac.kr

(a) This is an Open Access article distributed under the terms of the Creative Commons Attribution Non-Commercial License (http://creativecommons.org/licenses/by$\mathrm{nc} / 3.0$ ) which permits unrestricted non-commercial use, distribution, and reproduction in any medium, provided the original work is properly cited.
}

As in the United States, Canada, and Europe, generic formulations of brand name medications become available in Korea 20 years after the appearance of the original compound. ${ }^{3,4}$ A generic formulation of clozapine would reduce medical costs for patients with chronic schizophrenia and their families. ${ }^{5}$ However, perhaps due to the association of generic clozapine with agranulocytosis and the resulting required monitoring, manufacturers of generic formulations have appeared hesitant to introduce them to the market. Moreover, because the process of approving generic medications is not as rigorous as that for the brand name versions, ${ }^{3}$ concerns over their true equivalence have been raised. Because high blood levels of clozapine are associated with adverse events including seizures, hypotension, and sedation ${ }^{6}$ and may be a risk factor for life-threatening gastrointestinal hypomotility, ${ }^{7}$ determining the bioavailability of generic clozapine is important 
for proper risk assessment.

Only two published studies have compared the bioavailability of generic and brand name clozapine in schizophrenic patients, both in Western countries. ${ }^{8,9}$ As clozapine plasma concentration determines clinical response in schizophrenic patients ${ }^{10}$ and bioavailability often varies with ethnicity, the bioavailability of generic clozapine should also be investigated in different ethnic groups. The objective of this study was to compare the steady-state pharmacokinetics and bioequivalence of generic clozapine (Clzapine, DongWha Pharmaceutical, Seoul, Korea) with those of brand name clozapine (Clozaril, Novartis, Basel, Switzerland) in Korean patients with schizophrenia.

\section{METHODS}

\section{Study participants}

Male and female patients with schizophrenia aged between 20 and 60 years were eligible for this multi-center (4 university hospital and 2 psychiatric hospital), open-label, randomized, crossover study. All patients had been stable on Clozaril for at least 3 months prior to the study, had been taking a stable dose over that period, and were able to tolerate doses $\geq 200$ $\mathrm{mg}$ /day during the study period. Women of childbearing potential were excluded from the study if they were pregnant or were taking oral contraception and were required to use safe contraceptive methods. All patients underwent a complete physical examination at screening, including routine laboratory tests and electrocardiography. Exclusion criteria included hypersensitivity to clozapine or other antipsychotics; total white blood cell count $<4000 / \mathrm{mL}$ or absolute neutrophil count $<2000$ /mL; significant orthostatic hypotension; drug-resistant hypertension; significant cardiovascular disease; significant renal disease $(\mathrm{CCr}<50 \mathrm{~mL} / \mathrm{min}$ or $\mathrm{BUN} \geq 30 \mathrm{mg} / \mathrm{dL})$; hepatic disease (ALT/AST $>3$ times the upper normal limit, total bilirubin $>$ twice the upper normal limit, or alkaline phosphatase $>$ twice the upper normal limit); hepatitis $\mathrm{B}$ or $\mathrm{C}$ virus carrier or positive test results for the HCV antibody; history of granulocytopenia, myeloproliferative disorder, or deficient bone marrow function; immunodeficiency including HIV positive/AIDS, hematologic malignancy, or history of bone marrow transplantation; history of gastrointestinal disease that could affect absorption (e.g., Crohn's disease, inflammatory intestinal disease, ulcer, or pancreatitis); history of gastrointestinal surgery except appendectomy or hemorrhoidectomy or paralytic ileus; concurrent psychiatric or neurological diagnosis including organic mental disorder, severe tardive dyskinesia, or idiopathic Parkinson's disease; seizures within 1 year before enrollment or history of anticonvulsant treatment; alcohol consumption $\geq 21$ units/week, where one unit is $10 \mathrm{~g}$ of pure alcohol or inability to abstain from drinking during the study period; alcohol or substance abuse, dependence, or intoxication; smoking within 3 months before enrollment or inability to quit smoking during the study period; inability to be sampled regularly; lactose or galactose intolerance, Lapp lactose deficiency, or glucose-galactose malabsorption; use of barbiturates or other enzyme-inducing or inhibitory medication within 1 month before study entry; receiving any medication that could affect study results within 10 days before study entry; donation of whole blood within 2 months or apheresis or transfusion within 1 month before study entry.

Prohibited medications during the study period included antipsychotics other than clozapine, medications known to suppress bone marrow function, monoamine oxidase inhibitors, CNS depressants including anti-histamines, hypotensors, or respiratory suppressants, and CYP450 inhibitors. Other medications were maintained throughout the study period.

\section{Study design}

This multi-center, open-label, randomized, inpatient, twoway crossover study compared the steady-state pharmacokinetics and bioequivalence of $100 \mathrm{mg}$ twice daily generic clozapine (Clzapine) tablets with $100 \mathrm{mg}$ twice daily Clozaril in stable schizophrenic patients.

Following screening (20-9 days prior to drug administration), eligible patients were randomly assigned to one of two sequences of treatment. During the 10 days in each treatment period (periods I and II), the patients received the study medication $100 \mathrm{mg}$ twice daily (8:00 AM and 8:00 PM). On the last 4 days of each 10-day treatment period, blood samples were taken at 7:30 AM to measure clozapine plasma concentration. On day 9 of each treatment period, the patients were admitted before 6:00 PM and had nothing by mouth after 10:00 PM. On the last day of each treatment period, blood samples for measurement of plasma clozapine concentrations and pharmacokinetic determination were taken just before patients received their morning dose of clozapine and at 0.25 , $0.5,1,1.52,2.5,3,3.5,4,6,8$, and 12 hours after the morning dose.

Primary steady-state pharmacokinetic parameters, determined on the last day of each study period, included peak plasma concentration $\left(\mathrm{C}_{\mathrm{max}, \mathrm{ss}}\right)$ and area under the concentration-time curve from zero to 12 hours $\left(\mathrm{AUC}_{0-12}\right)$. Secondary pharmacokinetic parameters were time to peak plasma concentration $\left(\mathrm{T}_{\max }\right)$, elimination half-life $\left(\mathrm{t}_{1 / 2}\right)$, and accumulation index (R). Clozapine plasma concentrations were determined using a previously validated liquid chromatography coupled with tandem mass spectrometry (LC-MS-MS) technique. ${ }^{11}$ Pharmacokinetic parameters were calculated by Phoenix 
Table 1. Demographic characteristics

\begin{tabular}{|c|c|c|c|c|}
\hline & Total $(\mathrm{N}=28)$ & Clzapine-Clozaril $(\mathrm{N}=14)$ & Clozaril-Clzapine $(\mathrm{N}=14)$ & . \\
\hline & $\mathrm{N}(\%)$ or mean $\pm \mathrm{SD}$ & $\mathrm{N}(\%)$ or mean $\pm \mathrm{SD}$ & $\mathrm{N}(\%)$ or mean $\pm \mathrm{SD}$ & p-value \\
\hline Sex (female) & $14(50.0)$ & $8(57.1)$ & $6(42.9)$ & 0.450 \\
\hline Age (years) & $41.8 \pm 8.9$ & $42.9 \pm 9.7$ & $40.7 \pm 8.2$ & 0.521 \\
\hline Weight (kg) & $66.2 \pm 11.0$ & $62.6 \pm 8.0$ & $69.7 \pm 12.8$ & 0.092 \\
\hline Height $(\mathrm{cm})$ & $164.1 \pm 8.6$ & $164.4 \pm 8.2$ & $163.8 \pm 9.3$ & 0.856 \\
\hline Smoking (\%) & & & & $>0.999$ \\
\hline Current & 0 & 0 & 0 & \\
\hline Quit & $8(28.6)$ & $4(28.6)$ & $4(28.6)$ & \\
\hline Never & $20(71.4)$ & $10(71.4)$ & $10(71.4)$ & \\
\hline Drinking (\%) & & & & 0.128 \\
\hline Current & $1(3.6)$ & 0 & $1(7.1)$ & \\
\hline Quit & $14(50.0)$ & $5(35.7)$ & $9(64.3)$ & \\
\hline Never & $13(46.4)$ & $9(64.3)$ & $4(28.6)$ & \\
\hline
\end{tabular}

WinNonlin software (Pharsight, CA, USA).

\section{Statistical analysis}

The significance of differences in demographic variables between groups was assessed by independent $t$-test or Fisher's exact test, and differences in mean logarithmic transformed (natural $\log$ ) values of the primary pharmacokinetic parameters, i.e., $\mathrm{AUC}_{0-12}$ and $\mathrm{C}_{\text {max,ss }}$, were assessed by analysis of variance (ANOVA). For all analyses, results were considered significant if $\mathrm{p}<0.05$. The two formulations were considered bioequivalent if the $90 \%$ confidence intervals (CI) for the logtransformed parameter ratios (generic/brand) were between 80 and $125 \%$.

\section{Ethics}

The study was conducted according to the Declaration of Helsinki and good clinical practices. Written informed consent was obtained from all subjects after an extensive explanation of the nature and procedures of the study. The study protocol was approved by the institutional review or ethics committee at each study site.

\section{RESULTS}

A total of 32 patients were screened, and 28 patients were eligible for the study. Patients' demographic characteristics did not significantly differ between groups (Table 1). Three patients were later excluded due to screening failure, and another withdrew consent. Among the remaining 28 patients, $22(78.6 \%)$ completed the study. Reasons for discontinuation were protocol violation (three patients), withdrawal of consent (two patients), and adverse events (one patient; clavicle fracture).

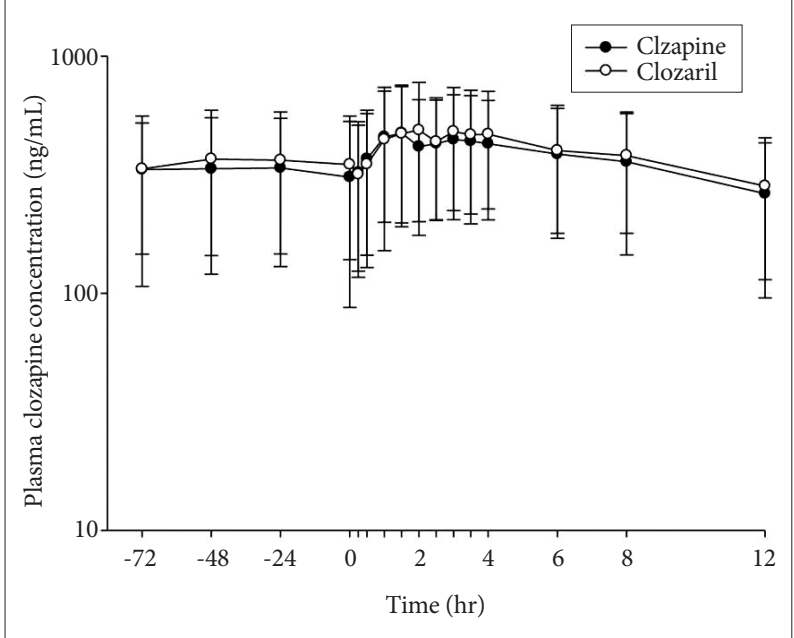

Figure 1. Mean plasma clozapine concentration after dosing on the day of area under the curve sampling over time (Log/Linear, $n=22$ ).

Steady-state conditions, defined as less than $30 \%$ difference between adjacent trough clozapine concentrations, were achieved in all patients in each treatment period. Mean clozapine plasma concentrations are shown in Figure 1. Clzapine (100-mg tablet) was found to be bioequivalent to Clozaril (100-mg tablet). The mean $\mathrm{C}_{\text {max ss }}$ was $524.62 \mathrm{ng} / \mathrm{mL}$ for $\mathrm{Cl}-$ zapine and $551.18 \mathrm{ng} / \mathrm{mL}$ for Clozaril. The mean $\mathrm{AUC}_{0-12}$ was $4479.90 \mathrm{hr} \cdot \mathrm{ng} / \mathrm{mL}$ for Clzapine and $4724.56 \mathrm{hr} \cdot \mathrm{ng} / \mathrm{mL}$ for Clozaril (Table 2). The $90 \% \mathrm{CI}$ of the ratios of the natural logarithmically transformed $\mathrm{C}_{\text {max,ss }}$ and $\mathrm{AUC}_{0-12}$ between Clzapine and Clozaril after a single oral dose of $100 \mathrm{mg}$ were 0.934 (0.849-1.028) and $0.936(0.869-1.008)$, respectively.

Five patients (20.8\%) among the 24 who received Clzapine reported 11 adverse events, and six adverse events were reported by four patients (15.4\%) among the 26 who received Clozaril ( $\mathrm{p}=0.721$ ) (Table 3 ). There was one serious adverse 
Table 2. Pharmacokinetic results

\begin{tabular}{lccc}
\hline & Clzapine $(\mathrm{N}=22)$ & Clozaril $(\mathrm{N}=22)$ & $90 \% \mathrm{CI}$ \\
\hline $\mathrm{C}_{\text {max }, \text { ss }}(\mathrm{ng} / \mathrm{mL})$ & $524.6 \pm 272.5$ & $551.18 \pm 263.3$ & $0.934(0.849-1.028)$ \\
$\mathrm{AUC}_{0-12}(\mathrm{hr} \cdot \mathrm{ng} / \mathrm{mL})$ & $4479.9 \pm 2495.0$ & $4724.6 \pm 2572.1$ & $0.936(0.869-1.008)$ \\
$\mathrm{T}_{\max }(\mathrm{hr})$ & $2.4 \pm 1.7$ & $2.8 \pm 1.9$ & \\
$\mathrm{t}_{1 / 2}(\mathrm{hr})$ & $12.0 \pm 6.9$ & $10.9 \pm 3.8$ & \\
$\mathrm{R}$ & $2.0 \pm 0.8$ & $1.9 \pm 0.4$ & \\
\hline
\end{tabular}

$\mathrm{C}_{\text {max,ss: }}$ steady-state peak plasma concentration, $\mathrm{AUC}_{0-12}$ : area under the concentration-time curve from zero to 12 hours, $\mathrm{T}_{\text {max }}$ time to peak plasma concentration, $\mathrm{t}_{1 / 2}$ : elimination half-life, $\mathrm{R}$ : accumulation index, $\mathrm{CI}$ : confidence interval of the ratios of the natural logarithmically transformed pharmacokinetic parameters

Table 3. Adverse events during study period

\begin{tabular}{lcc}
\hline & Clzapine (N=24) & Clozaril (N=26) \\
\hline Nausea & $1(4.2 \%)$ & 0 \\
Dyspepsia & $3(12.5 \%)$ & $1(3.8 \%)$ \\
Pharyngotonsilitis & 0 & $1(3.8 \%)$ \\
Nasopharyngitis & 0 & $1(3.8 \%)$ \\
Headache & 0 & $1(3.8 \%)$ \\
Tremor & $1(4.2 \%)$ & 0 \\
Pyrexia & $1(4.2 \%)$ & $1(3.8 \%)$ \\
Ocular discomfort & $1(4.2 \%)$ & 0 \\
Clavicle fracture & 0 & $1(3.8 \%)$ \\
Decreased appetite & $1(4.2 \%)$ & 0 \\
Apathy & $1(4.2 \%)$ & 0 \\
Dysmenorrhea & $1(4.2 \%)$ & 0 \\
Seborrhoeic dermatitis & $1(4.2 \%)$ & 0 \\
\hline
\end{tabular}

event, a fall causing a clavicle fracture. The patient stopped taking the study medication and discontinued the study. There were no significant differences or clinically significant changes on physical examination or in vital signs, ECG, or laboratory tests between groups (data not shown).

\section{DISCUSSION}

In this study, the generic clozapine (Clzapine) 100-mg tablet was found to be bioequivalent to the brand name clozapine (Clozaril) 100-mg tablet in Korean schizophrenic patients. The mean plasma concentration profiles $\left(\mathrm{AUC}_{0-12}\right.$ and $\mathrm{C}_{\text {max,ss }}$ ) were similar in the 22 patients who completed the study, and the $90 \%$ CIs for the ratios of natural logarithmically transformed $\mathrm{AUC}_{0-12}$ and $\mathrm{C}_{\text {max }, \mathrm{ss}}$ were within the $80-125 \%$ range.

In a previous study comparing brand name and generic clozapine, ${ }^{9}$ the $\mathrm{AUC}_{0-12}$ was 2547 and 2781 and $\mathrm{C}_{\text {max,ss }}$ was 317 and 358 for brand name and generic clozapine, respectively. These values are lower than those measured in the present study, which could be explained by ethnic differences, as the demographic distribution in the previous study was $66.7 \%$ Caucasian, $16.7 \%$ Black, and only $16.7 \%$ other ethnicities. ${ }^{9}$ A study investigating clozapine dosage and plasma clozapine levels in Asian versus Caucasian patients with chronic schizophrenia on stable maintenance treatment ${ }^{12}$ found similar plasma clozapine levels between the two groups, although Asian patients received a significantly lower mean clozapine dose than did Caucasians. This finding was significant after controlling for gender, body mass index, and cigarette and alcohol use. This inter-ethnic difference likely results from differences in metabolism including phase I reactions such as oxidation, reduction, and hydrolysis by cytochrome P450 (CYP450) enzymes and phase II conjugation reactions. ${ }^{13}$ In these metabolic processes, CYP450 is the most widely studied; the CYP1A2 isoform is particularly relevant to clozapine metabolism. Kall and Clausen ${ }^{14}$ reported that CYP1A2 activity is 1.54 fold higher in Swedes than in Koreans, and lower CYP1A2 activity has been found in Asian and African populations compared with Caucasians. ${ }^{15}$

In the present study, the $90 \%$ CIs for the mean log-transformed $\mathrm{AUC}_{0-12}$ ratio and $\mathrm{C}_{\text {max,ss }}$ were less than 1.0, suggesting lower drug exposure in patients receiving generic clozapine (Clzapine) than in those receiving Clozaril. As the US and Korea FDA requires that the $90 \% \mathrm{CI}$ of the difference in the means of log-transformed $\mathrm{C}_{\max , s \mathrm{~s}}$ and $\mathrm{AUC}_{0-12}$ of the two products be within $80-125 \%$ to define two compounds as bioequivalent, differences in drug exposures from generic and branded versions can be as large as $20-25 \%$. Though such variations are not significant for most drugs, they might be important in the case of clozapine (Borgherini 2003) because of its poor water solubility ${ }^{16}$ and narrow therapeutic index. ${ }^{17}$ Evidence for this conclusion comes from a previous study comparing generic clozapine (Zenith Goldline) and Clozaril in schizophrenic patients, ${ }^{18}$ which found that more patients experienced relapse or worsened when they were switched from Clozaril to generic clozapine than when drugs were given in the reverse order. Further, patients receiving Clozaril scored significantly better on the Clinical Global Impressionimprovement (CGII) Scale and Brief Psychiatric Rating Scale (BPRS). These results are in line with previous pharmacokinetic findings comparing Clozaril with the same generic clo- 
zapine. In that study, the mean log-transformed $\mathrm{C}_{\text {max,ss }}$ differed significantly between formulations, and the $90 \% \mathrm{CI}$ of the ratio of these values fell outside the $80-125 \%$ range, although the CI for the ratio of log-transformed AUC was within the acceptable range. ${ }^{8}$ The results of the present study suggests that the clinical effectiveness of the two formulations should be investigated in the Korean population.

In the study sample, generic clozapine (Clzapine, 100-mg tablet) appeared to be bioequivalent to brand name clozapine (Clozaril, 100-mg tablet) according to regulatory definitions employed in the US and Korea.

\section{Acknowledgments}

This study was supported by DongWha Pharmaceutical Co. Ltd., Seoul, Korea.

\section{REFERENCES}

1. Solanki RK, Singh P, Munshi D. Current perspectives in the treatment of resistant schizophrenia. Indian J Psychiatry 2009;51:254-260.

2. Dold M, Leucht S. Pharmacotherapy of treatment-resistant schizophrenia: a clinical perspective. Evid Based Ment Health 2014;17:33-37.

3. Desmarais JE, Beauclair L, Margolese HC. Switching from brand-name to generic psychotropic medications: a literature review. CNS Neurosci Ther 2011;17:750-760.

4. Korea Food and Drug Administration. Guideline for bioequivalence test (minimum requirements) [in Korean]. Available at: http://www.mfds. go.kr/index.do? $\mathrm{mid}=695 \& \mathrm{seq}=734 \& \mathrm{cmd}=\mathrm{v}$ (Accessed November 24, 2009). http://betest.kfda.go.kr/country/country01.php?p=1. (Accessed January 5 2015)

5. Fischer MA, Avorn J. Economic consequences of underuse of generic drugs: evidence from Medicaid and implications for prescription drug benefit plans. Health Serv Res 2003;38:1051-1063.

6. Stark A, Scott J. A review of the use of clozapine levels to guide treatment and determine cause of death. Aust N Z J Psychiatry 2012;46:816-
825.

7. Palmer SE, McLean RM, Ellis PM, Harrison-Woolrych M. Life-threatening clozapine-induced gastrointestinal hypomotility: an analysis of 102 cases. J Clin Psychiatry 2008;69:759-768.

8. Lam YW, Ereshefsky L, Toney GB, Gonzales C. Branded versus generic clozapine: bioavailability comparison and interchangeability issues. J Clin Psychiatry 2001;62(Suppl 5):18-22; discussion 23-24.

9. Sramek JJ, Anand R, Hartman RD, Schran HF, Hourani J, Barto S, et al. A bioequivalence study of brand and generic clozapine in patients with schizophrenia - Pharmacokinetic and tolerability findings. Clin Drug Invest 1999;17:51-58.

10. Potkin SG, Bera R, Gulasekaram B, Costa J, Hayes S, Jin Y, et al. Plasma clozapine concentrations predict clinical response in treatment-resistant schizophrenia. J Clin Psychiatry 1994;55(Suppl B):133-136.

11. Song M, Yu X, Zhao H, Hang T, Yang L, Xu W. LC-MS-MS determination and pharmacokinetic study of clozapine in human plasma. Chromatographia 2009;69:1049-1054.

12. Ng CH, Chong SA, Lambert T, Fan A, Hackett LP, Mahendran R, et al. An inter-ethnic comparison study of clozapine dosage, clinical response and plasma levels. Int Clin Psychopharmacol 2005;20:163-168.

13. Chaudhry IB, Neelam K, Duddu V, Husain N. Ethnicity and psychopharmacology. J Psychopharmacol 2008;22:673-680.

14. Kall MA, Clausen J. Dietary effect on mixed function P450 1A2 activity assayed by estimation of caffeine metabolism in man. Hum Exp Toxicol 1995;14:801-807.

15. Relling MV, Lin JS, Ayers GD, Evans WE. Racial and gender differences in $\mathrm{N}$-acetyltransferase, xanthine oxidase, and CYP1A2 activities. Clin Pharmacol Ther 1992;52:643-658.

16. Hopfinger AJ, Esposito EX, Llinas A, Glen RC, Goodman JM. Findings of the challenge to predict aqueous solubility. J Chem Inf Model 2009; 49:1-5.

17. Khan AY, Preskorn SH. Examining concentration-dependent toxicity of clozapine: role of therapeutic drug monitoring. J Psychiatr Pract 2005;11:289-301.

18. Kluznik JC, Walbek NH, Farnsworth MG, Melstrom K. Clinical effects of a randomized switch of patients from clozaril to generic clozapine. J Clin Psychiatry 2001;62(Suppl 5):14-17; discussion 23-24. 